\title{
Introduction of a Public Sector e-Procurement Solution: Lessons Learned from Disappointing Adoption
}

\author{
John Krogstie \\ IDI, NTNU, Trondheim, NO \\ krogstie@idi.ntnu.no
}

\begin{abstract}
In this article, we look at the reasons why the introduction of the public sector Internet Marketplace - ehandel.no - has thus far not been a success in the County Municipality of Sør-Trøndelag (STFK), as compared to the original ambitions regarding usage volume for this channel. To look into the situation, we have interviewed users of ehandel.no in STFK, and in other public organizations which are seen as successful (given their usage volume objectives), such as Trondheim municipality. We have used various acceptance theories in order to analyze why the users accept the same system to different degrees. The theories were utilized prior to the interviews in order to formulate interview questions. Afterwards, we used the same theories to analyze the results. The results indicate that good product catalogues, motivated users, compulsory use of the system when possible, and renegotiation of contracts with the suppliers are some of the most important prerequisites in order to achieve success using ehandel.no.
\end{abstract}

Keywords: E-Business and E-Government Information Systems, transfer and diffusion of information technology

\section{Introduction}

An electronic marketplace is defined as: "An Internet-based solution that connects businesses that are interested in buying and selling goods or services to each other" (Lipis et al, 2000). This is also the purpose of the public sector marketplace ehandel.no. In 1999, under the auspices of the Ministry of Trade and Industry, the Program for Electronic Trade in the Public Sector was started. One of the primary goals of this project was to get a public sector marketplace established (ECommerce Secretariat, 2001). A member of the public sector who wishes to make use of electronic commerce to purchase goods must subscribe to two services: an e-commerce platform and an end-user application. The e-commerce platform consists mainly of functionality for the distribution of the supplier product catalogues,

Please use the following format when citing this chapter:

Krogstie, J., 2008, in IFIP International Federation for Information Processing, Volume 274; Advances in Information Systems Research, Education and Practice; David Avison, George M. Kasper, Barbara Pernici, Isabel Ramos, Dewald Roode; (Boston: Springer), pp. 203-214. 
searching these catalogues, retrieval of one's own purchase statistics, and transmission of purchase orders. The end-user application provides access to the functionality in order to place, accept and send orders, as per entered agreements. It also manages transfer of information regarding completed transactions to the economic and invoice systems.

Introducing electronic commerce does not need to be a complex process; everything depends upon the size of the organization, as well as the level of ambition one has. An important aspect of introducing electronic commerce is identifying the portion of the purchase volume and transactions that are suitable for ecommerce. Analyses show that it is possible to support approximately $30 \%$ of the operation purchases (money-value) with an electronic commerce solution. These purchases typically represent $50 \%$ of the total number of invoices (E-Commerce Secretariat, 2002).

The main objective of the public sector Marketplace is (E-Commerce Secretariat, 2001): "Use of electronic commerce in the public sector shall contribute to the considerable decline in acquisitions costs and to the raising of the quality of the public procurement processes. The freeing of resources shall contribute to allowing public offices to concentrate on their primary tasks to a greater degree."

It was originally an objective to sell for NOK 1 billion in the Marketplace by 2003. This figure was first reached in 2007. Simultaneously, sales in the public sector reach approximately NOK 120 billion every year.

In 2002, a pilot project for the establishment of the public sector Marketplace was started. The project had 14 participants, among them, the County Municipality of Sør-Trøndelag (STFK) and Trondheim Municipality ${ }^{1}$. The pilot project lasted from December 2001 to May 2002. At the end of the pilot project, both Trondheim Municipality and STFK concluded that they could receive substantial profits by subscribing to the solution on a permanent basis, and the solution was introduced for normal use. After the introduction of the solution, progress has gone slow up until today (winter 2008). Few buyers have used the system, and economic benefits have not yet been observed. On the other hand, in Trondheim Municipality, the use and acceptance of the system has been much higher.

In the next chapter, we describe the problems at hand and theory backgrounds, focusing on relevant theories regarding acceptance of new technology. Thereafter, the research method is described. Results from the interviews are analyzed, and we suggest what can be done to increase use and acceptance of the system. In the final chapter, we present a conclusion in which we discuss results, weaknesses in the method we have used, and suggest further work.

\footnotetext{
1 Trondheim Municipality is part of the county municipality of Sør-Trøndelag. Municipalities and county municipalities have the responsibility of different public services, e.g. is it the County Municipality that has the responsibility for high schools, both in Trondheim and in the neighboring Municipalities. Primary schools in Trondheim on the other hand, is the responsibility of Trondheim Municipality
} 


\section{Problems and Theories}

An analysis of the situation in the STFK on January 1, 2002 revealed a large improvement potential with the introduction of an e-commerce system. There were a large number of small and medium-sized purchases outside of the general agreements that involved considerable additional costs. $97 \%$ of the suppliers represented just $20 \%$ of the purchasing value. Approximately $80 \%$ of the invoices were derived from purchases under NOK 5000, and with an average administrative cost for the ordering, stock receipt and invoice process of NOK 450 per invoice, this involved considerable amounts each year. At that time, general agreements were drawn up for approximately $45 \%$ of the total purchases (the County Municipality of Sør-Trøndelag, 2006). Agreement loyalty was poor. Orders to suppliers were made independent of agreements, set prices, ordering terms and delivery terms.

Electronic ordering of products and invoice management showed a profit potential that STFK wanted to bring out. After an invitation from the Ministry of Trade and Industry (NHD), the Chief Administrative Officer decided that STFK should take part as a pilot in the e-commerce project. In addition to qualitative benefits, such as better information and communication, improved financial management and time freed up for service and professional focus, it was calculated that STFK could receive a profit of somewhere between NOK 8 and 11.5 million per year by introducing an e-commerce system (County Municipality of SørTrøndelag, 2006).

Our problem at hand was:

"What can explain STFK's lack of success with the introduction of the Marketplace, ehandel.no ?"

\subsection{Acceptance Theories}

In order for the introduction of a new IT system to be a success, it is necessary that potential users effectively use the system. Since we had witnessed that the use in Trondheim municipality first became widespread when the use of the system was enforced (on both the purchaser and supplier side), we wanted to investigate system acceptance. There are several models and technology acceptance theories, among them: Diffusion theory (Davis, 2003, Venkatesh et al, 2003), Theory of Reasoned Action (TRA) (Ajzen and Fishbein, 1980), Technology Acceptance Model (TAM and TAM2) (Davis, 1989, Davis, Bagozzi and Warshaw, 1989; Venkatesh et. al., 2003), and ITPOSMO (Heeks, 1999). The theories have roots in information systems, psychology, and sociology. In this work, we have chosen to use several of these in order to investigate our problem. Due to page limitations, these are only briefly described as part of the analysis. 


\subsection{Method}

It has attempted to define the advantages and influences of electronic Marketplaces, but has not yet arrived at general theories that say anything about what makes an enterprise accept and use electronic marketplaces (Kioses, Pramatari, and Doukidis, 2006).

We assessed the evaluation methods questionnaires and interviews in order to collect data. Since we wished to go in-depth and we did not have a deep understanding of the situation beforehand, we chose to collect the information via interviewing the purchasers (i.e. the potential primary users of the system). This also provided us with the possibility of being exploratory during the interviews, and made it possible for the informants to elaborate on their opinions. Therefore, we chose a semi-structured form of interview. 42 questions were formulated based on the different acceptance theories, but it wasn't necessary for us to slavishly follow wording or question sequence, as one does in a structured interview (Rogers, Preece and Sharp, 2002). Online interviews, for example utilizing email are a valuable method to use when one wishes a quick response from users (Rogers, Preece and Sharp, 2002). We chose to carry out interviews in this way for those buyers that we did not have the opportunity of meeting personally. Due to the fact that we knew who the answers came from, we were able to pose follow-up questions.

The buyers in STFK can be roughly divided into three groups: schools, dental clinics, and management and administration. We have interviewed at least four people from each of these groups. We also interviewed those responsible for purchases at the local university (NTNU) and Trondheim municipality, both of which have been recognized as having success with the introduction of the marketplace. We interviewed both buyers who use the marketplace and those who do not (although they were expected to). In total, we interviewed 17 people, 6 of these interviews were face-to-face. The interviews took place in November 2006.

After an interview, we wrote a report and sent this back to the respondent so that he/she would have the opportunity to change, delete or add information.

\section{Results and discussion}

We here present the results from the study, structured according to the various acceptance theories.

\subsection{Diffusion Theory}

Diffusion theory mentions five factors that influence whether or not a user accepts a system: 
Relative advantage; to what degree the user regards the innovation as better than that which it replaces: Very few users perceive the marketplace as better than that which it replaces (telephone, telefax, and/or the suppliers own websites). No one we talked to thought that it was quicker to order products through the marketplace, not even those who eventually had received some experience making use of it. The dentists mainly have one supplier that they use - the Norwegian Dental Depot. This supplier has its own web shop. Several dentists mentioned that they prefer to purchase here because the products are placed, for them, in a logical, hierarchical structure. Consequently, one can navigate to a product, even though one doesn't know the name or article number, and thus would not have found it in an ordinary search.

A disadvantage that was mentioned is that the ordering must go through an approver before it is sent to the supplier, even though one has been authorized to send in orders. This additional element can result in delays since the approver can be out of town, or not have the time to approve the order right away.

Compatibility; to what degree an innovation is perceived as consistent with existing values, needs and experiences of potential users: We discovered that most employees were satisfied with the way in which they already ordered products. We were told from one of the administrative units that: "I have honestly never been into the marketplace... I have been issued a code or something, but I haven't had a use for it. (...) Sorry, that's just the way it is!" This reflects the attitude we saw with many. They don't see the need for a new system.

Something we discovered at a high school in the district, a problem the procurement service at STFK could confirm, was that two wishes they have in the districts cannot be fulfilled by the marketplace for the time being. Firstly, they want to support the local community by purchasing from the local suppliers. This is often not possible since these local suppliers are seldom a part of the marketplace. Secondly, the purchasers often need to receive the products on short notice, and the larger suppliers often deliver goods to the districts only once a week.

Complexity; to what degree an innovation is perceived as being difficult to understand and use: Many users think that the marketplace is difficult to understand and use. In particular, they think that it is difficult to find the products that they wish to buy. During the interviews, it was mentioned that it is frustrating that the product numbers are in different formats and that there are too few search criteria. The majority of users think that the product catalogues are not good enough, and that this is the biggest problem with using the marketplace. Many users are disappointed that the development of the marketplace has been so late and that it still has not become easier to find the products that they want. The supplier has given a free course in catalogue construction for suppliers, but very few showed up (County Municipality of Sør-Trøndelag, 2005).

Observability; to what degree the results of an innovation are visible to others: To a certain degree, one has attempted to influence this factor in STFK awarding those schools who had the greatest number of purchases on the marketplace (County Municipality of Sør-Trøndelag, 2005). A problem was that often it was the same schools that won every time. Further, several employees were displeased 
with the concept because, in a way, it was perceived that one was awarded for having used the most money.

Trialability; to what degree an innovation can be experimented with before it is finally used: Few users in STFK had the possibility of doing this.

\section{$3.2 T R A / T A M$}

Theory of Reasoned Action (TRA) is a model designed to explain human behavior (Ajzen and Fishbein, 1980). The model is based upon social psychology and the assumption that people use the information available to them in a reasonable manner when they make decisions. TRA's three components are behavioral intention, attitude and subjective norm (Davis, 2003). Technology Acceptance Model (TAM) (Davis, 1989) is based upon TRA, but is designed particularly in order to explain acceptance and use of information technology. The model can be used to foresee whether a system will be accepted by users, or in order to explain why a system is not adopted as it should be. They use two deciding factors in order to explain why people accept or reject information technology.

Perceived usefulness; the extent to which a person believes that a system will help them perform their job better. There are few positive feelings connected to the use of the Marketplace, meaning that perceived usefulness is small. Very few users in the County Municipality believe that the system will help them improve their job performance

Perceived ease of use; the degree to which a user believes the system to be free from effort. The user in STFK did not experience that the system is free from effort. Many think that they have to use a lot of time and energy on the system. As indicated also above, due to the poor product catalogue, other systems (e.g. the general web-shop of the supplier) were perceived to be easier to use than ehandel.no

\subsection{TAM2}

TAM 2 extend TAM on a number of areas. Here we present findings in light of the factors in TAM2.

Voluntariness; the extent to which the person perceives the decision to adopt an innovation as voluntary: The use of the marketplace is not voluntary. The decision to use electronic commerce in the County Municipality is taken and the users must comply. They are still not penalized if they do not make use of the marketplace, which can lead to many viewing the use as voluntary after all. For those operations that we interviewed, the number of purchasers who use the marketplace was low - nowhere was it over half. As mentioned above when discussing $o b$ servability above, STFK had monthly awards to the school that relatively pur- 
chased the most via the Marketplace. This may have contributed to the schools viewing use of the Marketplace as voluntary, even though at the same time, they had received letters from the county executive stating that they must use the Marketplace for those suppliers that are associated with it (the County Municipality of Sør-Trøndelag, 2005).

Experience; how much experience one has using the system, or other similar systems: Among those who use electronic commerce in the high schools, a large number are cleaning personnel, cafeteria workers and janitors. These are occupational groups that often use computers very little in their daily duties. In addition, these can be people in an age group that seldom uses computers in their leisure time. When one is not very computer literate, one is often extra afraid of the consequences of doing something wrong. Consequently, one rather prefers to use more traditional methods of ordering, such as the telephone and telefax.

Many users in the County Municipality do not have much experience with similar systems. We received confirmation that the system functions much better for those who use the marketplace regularly than for those who seldom purchase products there.

Subjective Norm; the degree to which the person perceives that the people who are important to him think that he should or should not perform the action: If employees see that it is important for their managers that they use the Marketplace, this can lead to increased use. On the other hand, we saw that few managers had a positive attitude. Trondheim municipality has used a great deal of time and energy to motivate the managers, and they themselves see this as a critical factor for success (Trondheim municipality, 2006). This supports that the factor of subjective norm is important.

Image; the degree to which use of an innovation will promote one's status in the social system: Use of the marketplace does not promote any special status within the social system that users are a part of. This means that this factor is not included regarding acceptance of the system.

Job relevance; the degree to which a person perceives the system as useful and relevant to his or her job: For many buyers in STFK, the marketplace is not particularly useful or relevant to the job. Purchasing products is only a small part of their jobs. Several think that it is easier to order on the telephone since this is something that they are used to.

Output quality; how well a system performs the tasks that are relevant to the job: Several users in STFK are very displeased with the product catalogues. Searches often give either too many or too few hits. This results in the system not satisfactorily carrying out tasks that are relevant to the job.

Results demonstrability: No one we talked to clearly saw the positive results of using the marketplace. Users from several units told us that they had not noticed any financial profit using the marketplace, and didn't see that the prices had become lower either as a consequence of renegotiated general agreements. This was particularly true of the dentists, since they mainly use only one supplier. The contract with this supplier is renegotiated regularly in any case. 


\subsection{ITPOSMO}

Here we analyze the results in light of the seven areas in ITPOSMO (Heeks, 1999).

Information: One condition necessary for a successful implementation of a reform is that the right amount of correct information reaches the users of the system. It was mentioned during interviews that some users received too much information during the first training session, so that it was difficult to extract what was essential in order to begin using the marketplace in an effective manner. Others remarked that they thought that they received too little training and that the information after the introduction had been lacking. Even if the users say that the catalogues are poor, it is difficult for the suppliers to know what they should change since the suppliers do not know how their own catalogues look for the users.

According to the one responsible for the marketplace in STFK, she seldom receives feedback from users regarding what they are displeased with, even though she encourages them to give it.

After having been in contact with purchasers at high schools, we see that the information regarding use of general agreements has not been sufficiently clear. Although users are obligated to use the suppliers on the marketplace, we have found several concrete examples in which other suppliers were used. Reasons for this are either that one receives lower prices from the supplier without a general agreement, or that one wishes to take local or timeliness considerations into account by using a local supplier. Some respondents said that they wanted more information regarding the use of general agreements.

One thing we found is that the majority of users used print catalogues to find the products that they wanted to buy. They go through and find the product, look at the picture, and make note of the product number. Afterwards, they search for the product on the marketplace. On the marketplace, the products are often poorly described and missing pictures. Therefore, it happens that users call the suppliers after they have found a product on the Marketplace. They do this to be sure that they have found the correct product.

Technology: Many users are displeased with the speed on the network connection, resulting in that product ordering takes a very long time. In addition, access to a computer can also be a problem. STFK has attempted to solve this by giving away computers, but due to lack of space, many declined the offer. In several dental clinics, the computer with an internet connection is in the lunch room. There are already computers in each office that do not have internet connections for security reasons. The fact that many have to share a computer means that the computer can often be in use when one has thought to order a product. If one does not have time to complete an order, something that is often the case in dental offices due to patient visits, someone else can take the computer in the meantime. Consequently, one must log in again to both the machine and the marketplace in order to continue with the order, and this is unnecessarily time-consuming. 
Trondheim municipality saw to it that high-speed internet and all technical equipment was in place before they introduced electronic commerce.

Processes: A process that the ICT service in STFK works hard in order to improve is integration between the purchasing system and the economy system. Invoice amounts and orders shall be matched in the accounting system so that the invoices go straight into the data system. According to the original plan, this should have been finished a year ago. When this process is in place, it will free up time that can be used for the business operation's primary job tasks. The procurement process is also not fully mature, and many purchases still take place outside of the general agreements.

Objectives: A common feature among most of those we spoke with is that in the beginning, they did not have a particularly positive attitude towards electronic commerce. Many felt that this was just a new initiative in a series of orders from the County Municipality. We were told at a dental office that: "It is a wide-spread belief at the clinics that in the last several years, we have been given more and more administrative work that steals valuable time from our primary job tasks.. (...) When this comes in addition to other administrative routines, which in a busy day is viewed as hassle and annoyance, the threshold is very high in order to use systems that are seen as a local setback."

Skills: An enthusiastic person is a good starting point in order to have success with electronic commerce. We were in contact with an enthusiast who saw the meaning in this. She took time to sit down and show each person how to use the marketplace in order to make the purchasing process simpler. When other employees have a positive and helpful co-worker in the vicinity, the threshold to ask for help is low, and this leads to uncertainties being cleared up and irritation disappearing. The use of this kind of super-users/enthusiast was not pursued in any planned manner though. Several respondents maintained that they do not have time to sit down and learn how to use electronic commerce, because they have so much to do with their other work tasks. Others say that although they have been trained and know how to use electronic commerce, they use more time ordering from the Marketplace than via telephone/telefax.

Management structures: In each unit there is a leader who decides how many purchasers there will be. Our findings show that there is up to 20 purchasers in one unit in the County Municipality. One success factor Trondheim municipality brought up were good foundations in the leadership and relatively few purchasers that had this as a main part of their job. Both Trondheim Municipality and SørTrøndelag County Municipality have used much time and energy on this. Trondheim municipality gathered all 220 unit leaders on a half-day course in groups of 30 to create motivation.

Other resources: There was no particular remarks related to this part of the ITPOSMO framework. 


\section{Reflection and Conclusion}

During this study, we have discovered many possible reasons for the lack of success with the introduction of the marketplace in STFK. The more important reasons are that users think they use too much time finding the products they wish to purchase, and that motivation among unit leaders and purchasers is low. In addition, many see the use of the marketplace as voluntary. We have shown that better product catalogues and search options are the most important things to tackle in order to improve user-friendliness. STFK will also most likely see an increase in purchases on the marketplace if they do what Trondheim Municipality did; enforce obligatory use. In Trondheim Municipality they require that the suppliers follow the agreement that buying and selling shall take place via the marketplace. At the same time, they should inform them that anything else will be seen as a breach of contract, and will lead to the cancellation of the agreement. In this connection, it is very important that employees remain loyal to the agreement. Although this appears to have been very effective in Trondheim Municipality, one should be cautious when introducing this kind of force and balance this with potentially negative side-effects. Introducing user support and ensuring that everyone has sufficiently high internet speed is also a good idea. STFK should use time to motivate the employees, and in particular, the unit leaders in addition to the purchasers. They should also renegotiate general agreements with suppliers and give electronic commerce the credit for the benefits this provides. It is important to inform employees about benefits since this will create motivation to use the Marketplace.

Theories we have used have pointed out factors we otherwise would not have been aware of such as the goal conflict in the district between supporting the local community vs. efficiency in the procurement processes, and they support that the findings we have made are real reasons that can explain lack of use.

\subsection{Discussion on Research Method}

We have been in contact with a total of 17 people. Thirteen of these are responsible for purchasing in STFK (i.e. they are actual purchaser and as such primary users of ehandel.no). We interviewed just 5 of the purchasers in STFK personally. This can be too few interviews to come to generally valid conclusions. In many of the email interviews, the responses were not as in-depth. Use of a broader survey would have perhaps been useful, providing us with more respondents. The response percent for the electronic interviews was approximately $60 \%$, which is a good response percent for this type of inquiry (Rogers, Preece and Sharp, 2002). We chose to in addition to interview the Head of Purchasing of Trondheim municipality towards the conclusion of our work, rather than at an earlier stage, in or- 
der to take advantage of the possibility of being able to verify findings and measures we had arrived at.

We had a follow-up meeting with STFK's purchasing service in order to present the measures we had arrived at. This was useful because, among other things, we discovered that one of the measures we originally had landed on had several more disadvantages than first thought.

Because one of our main measures is that the supplier's product catalogues should be improved, it would have been appropriate to contact one or more suppliers on the Marketplace in order to get a better idea of their situation.

The frameworks we have used in order to understand acceptance of technology are diffusion theory, TRA/TAM, TAM2 and ITPOSMO. They have similarities, but emphasize slightly different things. They were used to form questions and to evaluate the information we collected. Since the TAM/TAM2 articles have a number of questions they have discovered useful to ask users, this model was a good start. The questions are a good starting point in order to ensure that one poses the most relevant questions when one is going to interview users regarding acceptance of a system, and in order to ensure that they are formulated in the correct manner. Regarding evaluation of the results, we think that TAM2 was a more complete model. Diffusion is the oldest acceptance theory, and this was also very useful. We see that all of the factors are involved in explaining lack of acceptance. TRA wasn't so relevant in our case, since this is a general model that can be used to explain almost all types of human behavior. Since TRA is built into TAM, it was not necessary to go in-depth into this. Diffusion, TRA, TAM and TAM2 have much in common. There is a reunified framework described in (Venkatesh et. al., 2003) called, Unified Theory of Acceptance and Use of Technology (UTAUT). It is claimed that this new model includes the factors that have shown to play the largest role concerning acceptance and use of new technology. We see in retrospect that this could have well been used instead of the four frameworks we used, but given the set of questions linked to the existing frameworks, we found it beneficial to use these. To cover the full UTAUT would probably also have resulted in a need to extend the survey form with additional questions, which might have resulted in lower response rate on the email interviews. ITPOSMO has a different slant than the others, which was very fitting since this focuses on the public sector in particular. This model alone would not have uncovered everything we have discovered though, so this, in combination with the diffusion theory and TAM2, provides the best explanation model in our situation.

\subsection{Further Work}

This is a qualitative study. It could be interesting to carry out an anonymous, quantitative study based upon the data we have collected. It might also be an idea to carry out a field study - that is, to observe the user in his/her daily work environment. One could then uncover information the user is unaware of or takes for 
granted. Tests for usability are a suitable method for identifying problems the user has with an application. Such tests can be completed and the results given to the supplier of the end-user application. It is also an idea to contact the suppliers. One should then find out what could motivate them to create good product catalogues.

In this work, we have gone in-depth into the introduction of the marketplace in the County Municipality of Sør-Trøndelag. It would also be interesting to take a closer look at other public sector operations, including those which have chosen not to introduce the marketplace. Electronic commerce is introduced in the public sectors of several countries. One possibility is to look closer at their systems, and compare these with the situation in Norway.

\section{References}

Ajzen, I. og Fishbein, M. (1980) Understanding attitudes and predicting social behaviour. Prentice-Hall.

County Municipality of Sør-Trøndelag (2005). Statusrapport (Status report) [Intern rapport utlånt av innkjøpstjenesten i Sør-Trøndelag Fylkeskommune] (Internal report loaned by the procurement service of the County Municipality of Sør-Trøndelag).

County Municipality of Sør-Trøndelag (2006). ESTER, e-handel i Sør-trøndelag fylkeskommune. status på innkjøp i fylkeskommunen. (ESTER: E-commerce in Sør-Trøndelag County Municipality. Status of purchases in the County Municipality). [Intern rapport utlånt av innkjøpstjenesten i Sør-Trøndelag Fylkeskommune]. (Internal report loaned by the procurement service of the County Municipality of Sør-Trøndelag).

Davis, C. (2003) Technologies and methodologies for evaluating information technology in business. IRM Press, 2003.

Davis, F. (1989) Perceived usefulness, perceived ease of use, and user acceptance of information technology. MIS Quarterly, 13(3).

Davis, F., Bagozzi, R. P. og Warshaw, P. R. User acceptance of information technology: A comparison of two theoretical models. Management Science, 35(8), 1989.

E-Commerce Secretariat (2001). "Elektronisk markedsplass for det offentlige: Sluttbrukerapplikasjon", (Electronic marketplace for the public sector: End-user application) http://www.ehandel.no/data/file/krav_sluttbrukerapplikasjon.pdf. Last visited 10.10.2007.

E-Commerce Secretariate (2002). "Veileder for forprosjekt - elektronisk markedsplass for det offentlige", (Guide to preliminary work - electronic Marketplace for the public sector) http://www.ehandel.no/data/file/file_110.pdf. Last visited 10.10.2007.

Heeks, R. (1999) Reinventing government in the information age. Routledge.

Kioses, E., Pramatari, K. og Doukidis, G. (2006) Factors affecting perceived impact of electronic marketplaces. Proceedings 19th Bled Electronic Commerce Conference, June 4-6, Bled, Slovenia.

Lipis, L. J., Byron, D., Villars, R. og Turner, V. (2000). "Putting markets into place: An emarketplace definition and forecast", http://www.e-consultancy.com/knowledge/whitepapers/ 75/putting-markets-into-place-an-emarketplace-definition-and-forecast.html. Last visited 10. 10.2007

Rogers, Y., Preece, J. and Sharp, H. (2002) Interaction Design. John Wiley.

Trondheim Municipality (2006) E-handel I Trondheim kommune Sluttrapport innføringsprosjekt. (E-commerce in Trondheim Municipality: Final report on introduction project) http://www.ehandel.no/data/file/file_308.pdf, Last visited 10.10.2007.

Venkatesh, V., Morris, M., Davis, G. og Davis, F. (2003) User acceptance of information technology: Toward a unified view. MIS Quarterly, 27(3). J. Krogstie 